\title{
Erratum to: An oversimplified picture of the climate behavior based on a single process can lead to distorted conclusions
}

\section{Richard S. Lindzen ${ }^{\mathrm{a}}$}

Alfred P. Sloan Professor of Atmospheric Sciences, Emeritus, Massachusetts Institute of Technology, Cambridge, USA

(C) The Author(s), under exclusive licence to Società Italiana di Fisica and Springer-Verlag GmbH Germany, part of Springer Nature 2021

\section{Erratum to: Eur. Phys. J. Plus (2020) 135:462 https://doi.org/10.1140/epjp/s13360-020-00471-z}

In the original published article the references have been ordered alphabetically by mistake. Now they are ordered by numbers.

The original article has been corrected. 